\title{
Studies on gas sensing performance of pure and modified barium strontium titanate thick film resistors
}

\author{
G H JAIN, L A PATIL*, P P PATIL ${ }^{\dagger}$, U P MULIK ${ }^{\dagger \dagger}$ and K R PATIL ${ }^{\#}$ \\ P.G. Department of Physics, Pratap College, Amalner 425 401, India \\ ${ }^{\dagger}$ Physical Sciences, North Maharashtra University, Jalgaon 425 001, India \\ ${ }^{\dagger}$ Centre for Materials for Electronics Technology, Pune 411008 , India \\ "National Chemical Laboratory, Pune 411 008, India
}

MS received 25 July 2006; revised 28 August 2006

\begin{abstract}
Barium strontium titanate $\left(\left(\mathrm{Ba}_{0.87} \mathrm{Sr}_{0.13}\right) \mathrm{TiO}_{3}-\mathrm{BST}\right)$ ceramic powder was prepared by mechanochemical process. The thick films of different thicknesses of BST were prepared by screen-printing technique and gas-sensing performance of these films was tested for various gases. The films showed highest response and selectivity to ammonia gas. The effect of film thickness on gas response was also studied. As prepared BST thick films were surface modified by dipping them into an aqueous solution of titanium chloride $\left(\mathrm{TiCl}_{3}\right)$ for different intervals of time. Surface modification shifted response to $\mathrm{H}_{2} \mathrm{~S}$ gas suppressing the responses to ammonia and other gases. The surface modification, using dipping process, altered the adsorbate-adsorbent interactions, which gave the unusual sensitivity and selectivity effect. Sensitivity, selectivity, thermal stability, response and recovery time of the sensor were measured and presented.
\end{abstract}

Keywords. $\quad\left(\mathrm{Ba}_{0.87} \mathrm{Sr}_{0 \cdot 13}\right) \mathrm{TiO}_{3}$ thick films; ammonia gas sensor; $\mathrm{H}_{2} \mathrm{~S}$ gas sensor; sensitivity; selectivity.

\section{Introduction}

The first semiconductor oxide gas sensors were reported by Seiyama et al in 1962. Since then, there have been numerous studies on other oxide semiconductors such as $\mathrm{SnO}_{2}, \mathrm{ZnO}, \mathrm{In}_{2} \mathrm{O}_{3}, \mathrm{TiO}_{2}, \alpha-\mathrm{Fe}_{2} \mathrm{O}_{3}, \mathrm{HfO}_{2}, \mathrm{WO}_{3}, \mathrm{BaSnO}_{3}$ (Seiyama et al 1962; Yamazoe et al 1983; Kabayashi et al 1988; Tamaki et al 1990; Lampe et al 1995; Nakamura et al 1998; Tao and Tsai 2002; Cantalini 2004). Semiconductor oxide gas sensors are extensively studied in order to improve their sensing characteristics, i.e. sensitivity, selectivity, stability, and response rate, to various kinds of gases and to meet the increasing needs of sensors in complicated systems and under strict conditions (Seiyama et al 1962; Yamazoe et al 1983; Kabayashi et al 1988; Tamaki et al 1990; Lampe et al 1995; Nakamura et al 1998; Tao and Tsai 2002; Cantalini 2004).

Detection of ammonia $\left(\mathrm{NH}_{3}\right)$ is required in many applications including leak-detection in air conditioning systems, sensing of trace amounts in air for environmental analysis (Groot 2004), breath analysis for medical diagnoses (Timmer 2004), animal housing (Groot 2004) and more. Generally, because it is toxic, it is required to be able to sense low levels of $\mathrm{NH}_{3}$, but it should also be sensitive to much higher levels. $\mathrm{NH}_{3}$ gas is very corrosive, often causing

*Author for correspondence (lapresearch@ rediffmail.com) existing $\mathrm{NH}_{3}$ sensors to suffer from drift and have short life times. There are many principles for measuring $\mathrm{NH}_{3}$ described in the literature (Timmer et al 2005; Yamazoe 2005). The ammonia sensors that have been manufactured in the largest quantities are mostly based on $\mathrm{SnO}_{2}$ sensors (Clifford and Tuma 1983; Huebner and Drost 1991; Srivastava et al 1994; Sberreglieri 1995; Imawan et al 2000; Zakrzewska 2001). These sensors are rugged and inexpensive.

A different approach to make selective metal-oxide gas sensor is by using metals or additives that enhance the chemisorptions of specific gases. $\mathrm{WO}_{3}$ based sensing material is demonstrated to respond to $\mathrm{NH}_{3}$ (Wang et al 2000; $\mathrm{Xu}$ et al 2000). Very low detection limits of $1 \mathrm{ppm}$ for ammonia sensing has been reported using a $\mathrm{WO}_{3}$ ammonia sensor with $\mathrm{Au}$ and $\mathrm{MoO}_{3}$ additives. This sensor is operated at an elevated temperature of more than $400^{\circ} \mathrm{C}$ (Xu et al 2000). Most sensors have much higher detection limits. Normal detection of these sensors ranges from 1-1000 ppm (Aslam et al 1999; Xu et al 2000). Another type of widely used ammonia sensor, employing electrolyte solutions with diaphragm electrodes, has major limitations due to the cost of fabrication and its relatively poor sensitivity and selectivity. Similarly, Pd gate metal oxide semiconductor device is also sensitive to ammonia but it does not offer sufficient selectivity, because ammonia is indirectly detected by sensing the hydrogen after decomposition (Lundström et al 1975; Winquist et al 1983). 
The perovskite oxides $\left(\mathrm{ABO}_{3}\right)$ were used as gas sensor materials for their stability in thermal and chemical atmospheres. In the last decade, perovskite oxide ceramics such as $\mathrm{BaTiO}_{3}$ (Ishihara et al 1995; Haueusler and Meyer 1996; Liao et al 2001; Tang et al 2003; Zhou et al 2003; Jain et al 2006) and (Ba, Sr) $\mathrm{TiO}_{3}$ (Slunečko et al 1992; Holc et al 1995; Tan et al 1999; Chen et al 2000; Zhu et al 2000; Agarwal and Sharma 2002; Roy et al 2005) have generated a lot of interest for chemical sensors. Modifications in microstructure, processing parameters and also concentration of acceptor/donor dopant can vary the temperature coefficient of the resistance and conductivity of $\mathrm{ABO}_{3}$ oxides. Sensors based on $\mathrm{ABO}_{3}$-type complex oxide material, of rare earth elements have an outstanding merit of their sensitivity and better selectivity. These characteristics can be controlled by selecting suitable A and B atoms or chemically doping $\mathrm{A}^{\prime}$ and $\mathrm{B}^{\prime}$ elements equivalent, respectively to $\mathrm{A}$ and $\mathrm{B}$ into $\mathrm{ABO}_{3}$ to obtain $\mathrm{A}_{x} \mathrm{~A}_{1-x}^{\prime} \mathrm{B}_{y} \mathrm{~B}^{\prime}{ }_{1-y} \mathrm{O}_{3}$ compound (Yan et al 1991; Kong and Shen 1996).

Gas sensing performance of screen-printed $\left(\mathrm{Ba}_{0.87} \mathrm{Sr}_{0 \cdot 13}\right)$ $\mathrm{TiO}_{3}$ (BST) thick films is studied here. Jain and Patil (2006) studied the sensing behaviour of pure and modified $\left(\mathrm{Ba}_{0.67} \mathrm{Sr}_{0.33}\right) \mathrm{TiO}_{3}$, and reported that unmodified and modified $\left(\mathrm{Ba}_{0.67} \mathrm{Sr}_{0.33}\right) \mathrm{TiO}_{3}$ are sensitive to $\mathrm{H}_{2} \mathrm{~S}$ gas. Here we report the effect of change in composition of BST, and on the sensing performance of $\left(\mathrm{Ba}_{0.87} \mathrm{Sr}_{0 \cdot 13}\right) \mathrm{TiO}_{3}$ and $\mathrm{TiO}_{2}-$ modified $\left(\mathrm{Ba}_{0.87} \mathrm{Sr}_{0 \cdot 13}\right) \mathrm{TiO}_{3}$. In the present study, it was observed that response to $\mathrm{NH}_{3}$ gas increases with increase in $\left(\mathrm{Ba}_{0.87} \mathrm{Sr}_{0.13}\right) \mathrm{TiO}_{3}$ film thickness up to certain limit, beyond that response decreases on further increase in thickness. However, Roy et al (2005) reported that the response to $\mathrm{NH}_{3}$ gas goes on increasing with film thickness. The sensitivity varied depending upon the thicknesses, microstructural variations, operating temperature and concentration of gas. $\left(\mathrm{Ba}_{0 \cdot 87} \mathrm{Sr}_{0 \cdot 13}\right) \mathrm{TiO}_{3}$ thick films were surface modified using titanium chloride $\left(\mathrm{TiCl}_{3}\right)$ solution by dipping technique. The surface modification shifts the sensitivity of $\left(\mathrm{Ba}_{0.87} \mathrm{Sr}_{0.13}\right) \mathrm{TiO}_{3}$ thick film from $\mathrm{NH}_{3}$ to $\mathrm{H}_{2} \mathrm{~S}$ gas.

\section{Experimental}

\subsection{Powder and paste preparation}

AR grade powders of $\mathrm{Ba}(\mathrm{OH})_{2} \cdot 8 \mathrm{H}_{2} \mathrm{O}, \mathrm{Sr}(\mathrm{OH})_{2}$ with $7: 1$ molar concentration and $\mathrm{TiO}_{2}$ were milled for $2 \mathrm{~h}$ using planetary ball mill to obtain fine-grained powder. The powder was then calcined at $1000^{\circ} \mathrm{C}$ for $6 \mathrm{~h}$.

The XRD spectrum of as prepared powder confirmed the sub-microcrystalline perovskite phase. The composition ratios $(\mathrm{Ba} / \mathrm{Sr})$ of the as prepared powder were confirmed using the microarea EDS analysis.

The BST powder was screen-printed using the procedure reported elsewhere (Jain and Patil 2006; Jain et al 2006) onto a glass substrate in the desired pattern. The films were fired at $550^{\circ} \mathrm{C}$ for $30 \mathrm{~min}$.

\subsection{Preparation of surface modified BST thick films}

The surface modified BST thick films were obtained by dipping them in a $0 \cdot 1 \mathrm{M}$ aqueous solution of titanium chloride $\left(\mathrm{TiCl}_{3}\right)$ for different intervals of dipping time: 5, 10, 20 and $30 \mathrm{~min}$. These films were dried at $80^{\circ} \mathrm{C}$, followed by firing at $550^{\circ} \mathrm{C}$ for $30 \mathrm{~min}$. These surface modified films are termed as ' $\mathrm{TiO}_{2}$-modified' films.

\subsection{Variation of thickness}

Films of various thicknesses were prepared by controlling the number of impressions of squeeze strokes. Different films of thicknesses: 1 BST $(17 \mu \mathrm{m}), 2$ BST $(33 \mu \mathrm{m})$, 3 BST $(48 \mu \mathrm{m})$ and 4 BST $(63 \mu \mathrm{m})$, were printed. The reproducibility in the thickness of the films was possible by maintaining proper rheology and thixotropy of the paste.

\subsection{Characterization}

The structural properties of powder were studied using RIGAKU model DMAX-2500 X-ray Diffractometer (XRD) with $\mathrm{CuK} \alpha$ radiation, having $\lambda=1.5406 \AA$. The microstructural and chemical compositions of the films were analysed using a scanning electron microscope (SEM, JEOL JED 6300) coupled with an energy dispersive spectrometer (EDS, JEOL JED 2300LA). The thickness of the thick films was measured using Taylor-Hobson (Talystep, UK) system. Thermogravimetric (TGA) analysis of the samples was carried out using a Mettler Toledo Star system-851 under similar conditions in static air. The sensing performance of the sensors was examined using a 'static gas sensing system' explained elsewhere (Jain and Patil 2006; Jain et al 2006).

\section{Results and discussion}

\subsection{Structural properties}

Figure 1 shows the X-ray diffractogram of screen-printed BST thick films fired at $550^{\circ} \mathrm{C}$ in air atmosphere.

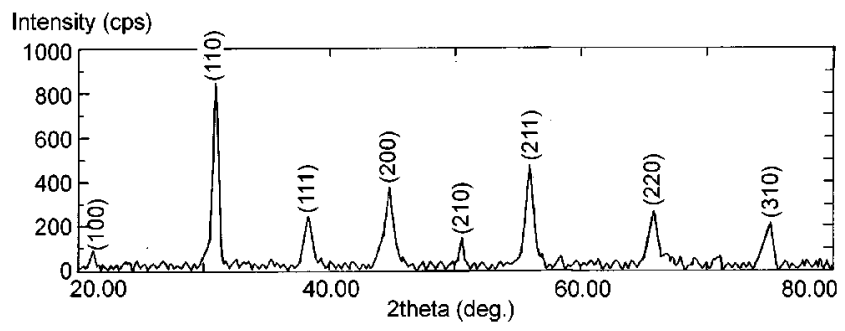

Figure 1. X-ray diffractogram of the BST thick films. 

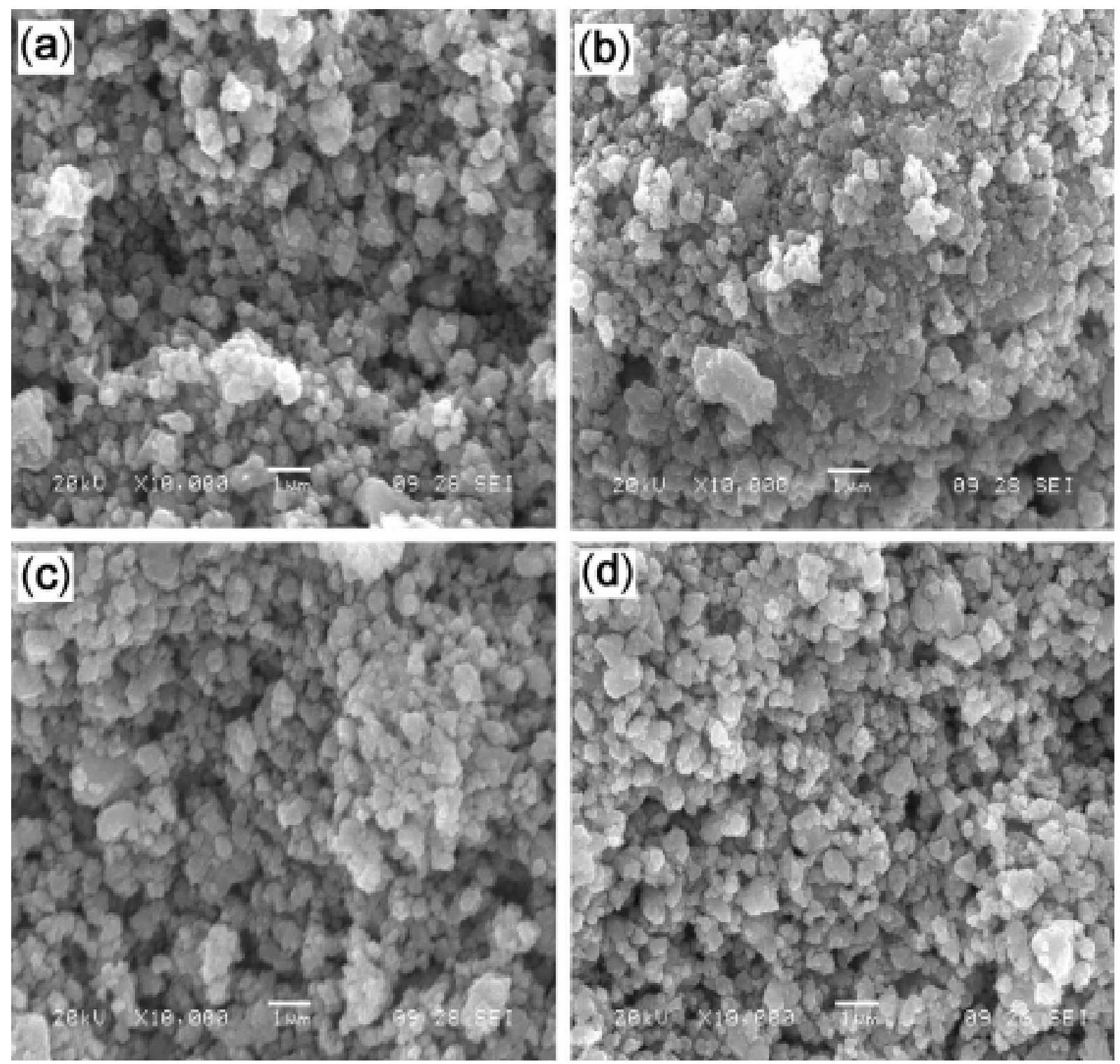

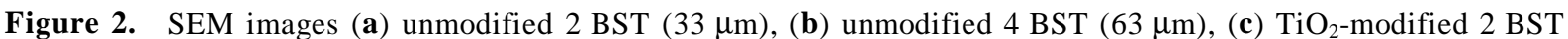
(dipped for $5 \mathrm{~min}$ ), and (d) $\mathrm{TiO}_{2}$-modified 2BST (dipped for $20 \mathrm{~min}$ ).

XRD analysis revealed that the material is polycrystalline in nature with tetragonal perovskite phases. The peak positions matched well with the ASTM data book, card no. 34-11 and the average grain size determined from Scherrer formula is estimated to be $264 \mathrm{~nm}$.

\subsection{Microstructural analysis}

Figure 2(a) depicts SEM image of unmodified 2 BST $(33 \mu \mathrm{m})$ thick film fired at $550^{\circ} \mathrm{C}$. The film consists of a large number of grains leading to high porosity and large effective surface area available for the adsorption of oxygen species. Figure 2(b) is the SEM image of the unmodified
4 BST film having larger thickness $(63 \mu \mathrm{m})$. It is clear from the figure that it is comparatively less porous and grains are agglomerated. Effective surface to volume ratio would be decreased and less number of oxygen ions would be adsorbed as compared to the film in figure 2(a). Figure 2(c) is the SEM image of a $\mathrm{TiO}_{2}$-modified $2 \mathrm{BST}(33 \mu \mathrm{m})$ film for the dipping time interval of $5 \mathrm{~min}$. The micrograph appears to consist relatively of smaller number of small particles distributed around the larger BST particles. The small particles would be of $\mathrm{TiO}_{2}$. Figure 2(d) is the SEM image of a $\mathrm{TiO}_{2}$-modified $2 \mathrm{BST}(33 \mu \mathrm{m})$ film for the dipping time interval of $20 \mathrm{~min}$. The micrograph appears to consist of a number of small particles distributed uniformly around the larger grains. The smaller particle may be at- 
Table 1. Elemental analysis of unmodified and $\mathrm{TiO}_{2}$-modified BST films.

\begin{tabular}{lccccc}
\hline & \multicolumn{5}{c}{ Dipping time (min) } \\
\cline { 2 - 6 } Element (wt\%) & 0 & 5 & 10 & 20 & 30 \\
\hline$(\mathrm{Ba}+\mathrm{Sr}+\mathrm{Ti})$ & $93 \cdot 16$ & $93 \cdot 23$ & $93 \cdot 33$ & 93.86 & $92 \cdot 86$ \\
$\mathrm{Ti}$ & 00 & $0 \cdot 22$ & $0 \cdot 30$ & 0.43 & 0.64 \\
$\mathrm{O}$ & $6 \cdot 84$ & $6 \cdot 55$ & $6 \cdot 37$ & $5 \cdot 71$ & 6.50 \\
$\mathrm{BST}$ & 100 & $99 \cdot 6323$ & $99 \cdot 4986$ & $99 \cdot 2813$ & 98.9304 \\
$\mathrm{TiO}_{2}$ & 00 & 0.3677 & 0.5014 & 0.7187 & 1.0696 \\
\hline
\end{tabular}

tributed to the $\mathrm{TiO}_{2}$ grains and the larger to BST. The film seems to be highly porous with a large effective area for oxygen adsorption.

\subsection{Quantitative elemental analysis of unmodified and $\mathrm{TiO}_{2}$-modified $\mathrm{BST}$ films}

The quantitative elemental composition of the film and wt. $\%$ of $\mathrm{TiO}_{2}$ and BST analysed using an energy dispersive spectrometer are presented in table 1 .

Stoichiometric (theoretically expected) wt\% of cations $(\mathrm{Ba}+\mathrm{Sr}+\mathrm{Ti})$ and anions $(\mathrm{O})$ are 85.02 and 14.98 , respectively. The wt $\%$ of constituent cations and anions in as prepared BST and $\mathrm{TiO}_{2}$-modified 2 BST were not as per the stoichiometric proportion and all samples were observed to be oxygen deficient, leading to the semiconducting nature of BST.

It is clear from table 1 that the weight percentage of $\mathrm{TiO}_{2}$ increased with dipping time. The film with a dipping time of $20 \mathrm{~min}$ is observed to be more oxygen deficient (5.71 wt $\%)$. The observed oxygen deficiency was expected to promote increased oxygen adsorption.

\subsection{Electrical conductivity}

Figure 3 shows the dependence of conductivity of BST films with temperature in air and $\mathrm{NH}_{3}$ ambient. Electrical conductivity of these films goes on increasing with increase in temperature in air and gas $\left(\mathrm{NH}_{3}\right)$ ambient, indicating negative temperature coefficient (NTC) of resistance. This shows the semiconducting nature of the films. Slopes of the graphs between 50 and $300^{\circ} \mathrm{C}$ are different for different curves.

\subsection{Thermal analysis}

Figure 4 shows the thermogravimetric profile of pure and $\mathrm{TiO}_{2}$-modified $2 \mathrm{BST}$ films. Table 2 lists the losses or gains in weight percentage of pure and $\mathrm{TiO}_{2}$-modified $2 \mathrm{BST}$ films in different ranges of temperature as observed from TGA. Comparatively a less weight loss and a more gain in the $\mathrm{TiO}_{2}$-modified 2 BST sample can be attributed to the

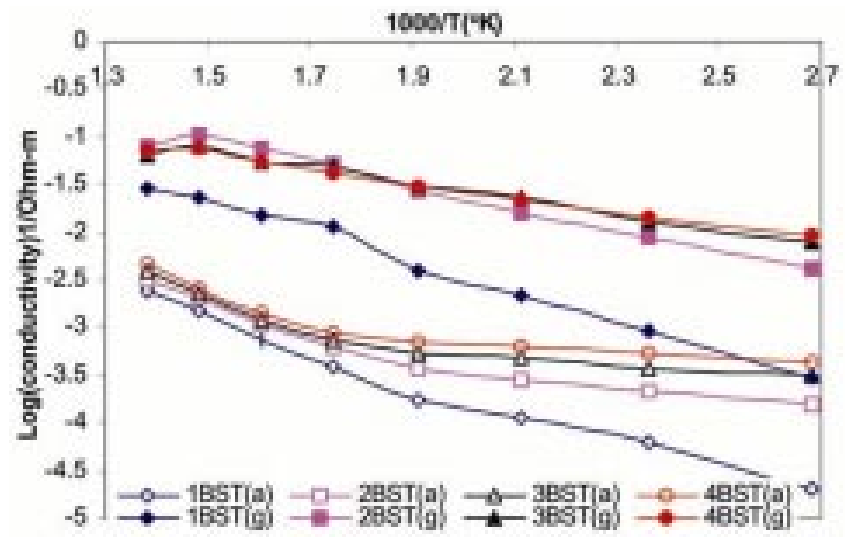

Figure 3. Variation of conductivity with operating temperature.

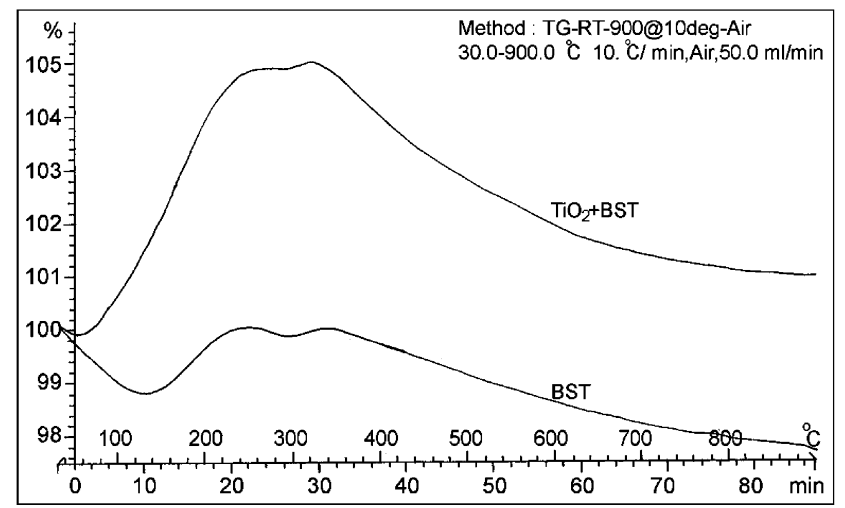

Figure 4. TGA of pure and $\mathrm{TiO}_{2}$-modified 2BST films.

adsorbed oxygen content. The film with $\mathrm{TiO}_{2}$ content of $0.7187 \mathrm{wt} \%$ was observed to contain the smallest amount of oxygen $(5.71 \mathrm{wt} \%$, table 1$)$, which could be attributed to the largest deficiency of oxygen in the film. It is, therefore, quite possible that the material would adsorb the largest possible amount of oxygen, showing a relatively larger gain in weight $(5 \mathrm{wt} \%)$ in the temperature range $30-320^{\circ} \mathrm{C}$. The $\mathrm{TiO}_{2}$ on the surface of modified sample would form misfit regions between the grains of BST and could act as an efficient catalyst for oxygenation. 
Table 2. Thermal analysis.

\begin{tabular}{lccrrr}
\hline & \multicolumn{2}{c}{ Pure 2BST } & & \multicolumn{2}{c}{$\mathrm{TiO}_{2}$-modified 2BST } \\
\cline { 2 - 3 } Temperature $\left({ }^{\circ} \mathrm{C}\right)$ & Loss $($ wt.\%) & Gain $($ wt. $\%)$ & Temperature $\left({ }^{\circ} \mathrm{C}\right)$ & Loss (wt.\%) & Gain (wt.\%) \\
\hline $30-25$ & $1 \cdot 20$ & - & $30-320$ & - & $5 \cdot 0$ \\
$125-245$ & - & $1 \cdot 20$ & $320-900$ & $4 \cdot 0$ & - \\
$245-290$ & $0 \cdot 20$ & - & & \\
$290-340$ & - & $0 \cdot 20$ & & \\
$340-900$ & $2 \cdot 25$ & - & & \\
\hline
\end{tabular}

\section{Sensing performance}

\subsection{Sensing characteristics}

Sensitivity is defined as the ratio of change in conductance of the sample on exposure to gas to the conductance in air.

$$
S=\frac{G g-G a}{G a}=\frac{\Delta G}{G a},
$$

where $G g$ and $G a$ are the conductances of the sample in the presence and absence of the test gas, respectively and $\Delta G$ the change in conductance.

The ability of a sensor to respond to certain gas in the presence of other gases is known as selectivity. The time taken for the sensor to attain $90 \%$ of maximum change in resistance on exposure to gas is the response time. The time taken by the sensor to get back $90 \%$ of the original resistance is the recovery time (Ishihara et al 1991).

\subsection{Unmodified BST films}

4.2a Sensitivity with operating temperature: Figure 5 shows the variation in the sensitivity to $\mathrm{NH}_{3}$ gas (300 ppm) with operating temperatures (for films of various thickness). It is noted from the graph that response increases with increasing temperature, and attains a maximum at $300^{\circ} \mathrm{C}$, and decreases with further increase in operating temperature for all thicknesses and a film thickness of $33 \mu \mathrm{m}$ is found to be most sensitive for sensing $\mathrm{NH}_{3}$ gas.

$4.2 \mathrm{~b}$ Variation of sensitivity with film thickness: Figure 6 shows the variation in the sensitivity with film thickness, and the sudden change in sensitivity at a particular thickness could be related to the porosity in the screenprinted film. The porosity appears to increase with increasing film thickness. Beyond a certain thickness limit the porosity may decrease due to increase in agglomeration. The increased porosity increases the in-pore adsorption of oxygen and tends to improve the adsorption-desorption mechanism of target gas.

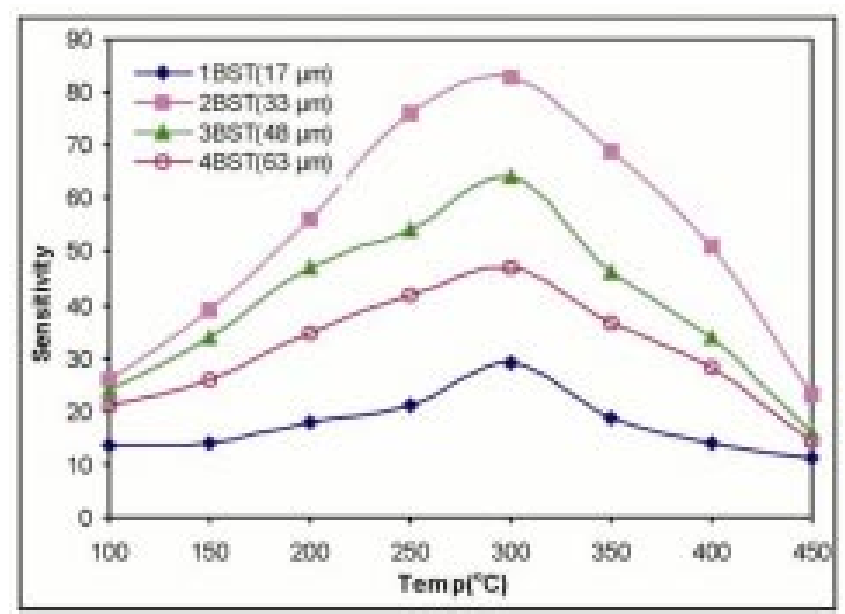

Figure 5. Variation of sensitivity with operating temperature for $300 \mathrm{ppm} \mathrm{NH}$ gas.

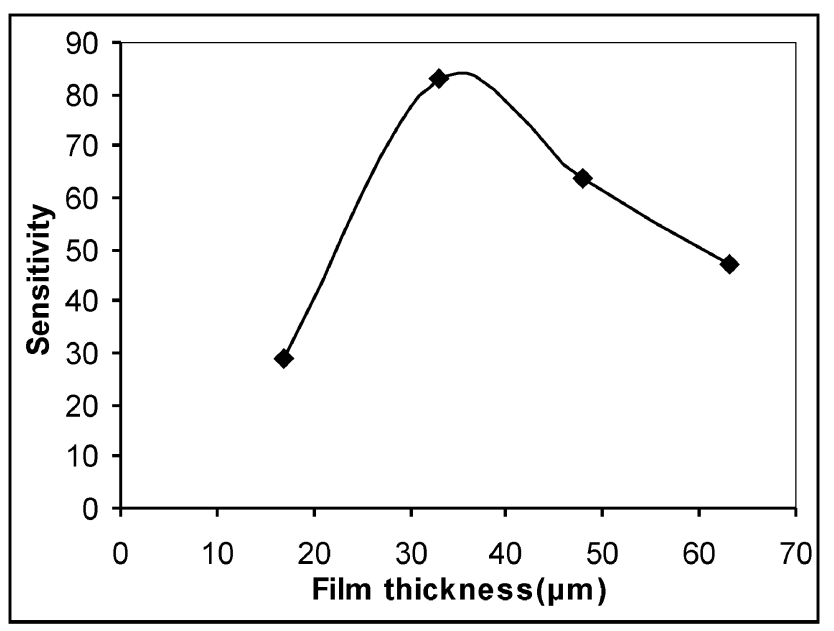

Figure 6. Variation of sensitivity to $\mathrm{NH}_{3}$ gas with film thickness.

\subsection{Response and recovery at different gas concentrations}

Figure 7 shows the response and recovery profiles of the most sensitive unmodified (2BST) film to ammonia gas 
at $300^{\circ} \mathrm{C}$ and it is observed that the response and recovery times increase as gas concentration increases.

Table 3 shows the values of response and recovery times at different gas concentrations. It is revealed that for lower gas concentration the response and recovery times are observed to be shorter, and become longer as gas concentration increases. Smaller the gas concentration faster would be the oxidation of $\mathrm{NH}_{3}$ gas and hence quick response and immediate recovery of the sensor are noted.

\section{$4.4 \mathrm{TiO}_{2}$-modified $2 \mathrm{BST}$ films}

4.4a Sensitivity and dipping time: Figure 8 shows the variation in the sensitivity of $\mathrm{TiO}_{2}$-modified $2 \mathrm{BST}$ films to $\mathrm{H}_{2} \mathrm{~S}$ and $\mathrm{NH}_{3}$ gas at an operating temperature of $300^{\circ} \mathrm{C}$, for films that were treated for different intervals of time for modification. It is clear from the figure that the response to $\mathrm{H}_{2} \mathrm{~S}$ gas goes on increasing with the increase of dipping time interval, and reaches a maximum at $20 \mathrm{~min}$, then decreases with further increase in dipping time while response to $\mathrm{NH}_{3}$ gas goes on decreasing with dipping time.

Unmodified sample is more sensitive to $\mathrm{NH}_{3}$ while $\mathrm{TiO}_{2}$-modified sample is more sensitive to $\mathrm{H}_{2} \mathrm{~S}$. The shift in the sensitivity of the modified film to $\mathrm{H}_{2} \mathrm{~S}$ gas could be attributed to surface modification. Surface modification

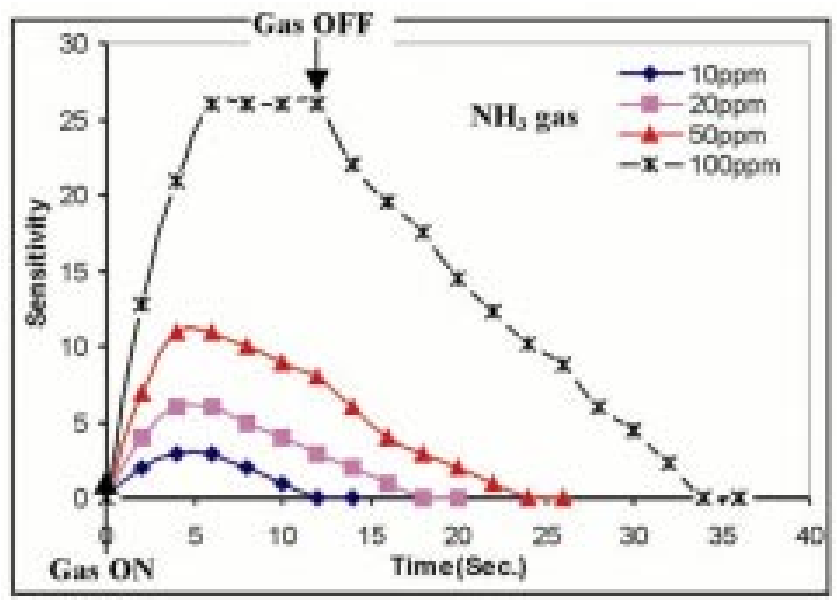

Figure 7. Response speed of the (2 BST) film at different $\mathrm{NH}_{3}$ gas concentrations.

Table 3. Response and recovery times with gas concentrations.

\begin{tabular}{lcc}
\hline $\begin{array}{l}\text { Gas concentration } \\
(\mathrm{ppm})\end{array}$ & $\begin{array}{c}\text { Response time } \\
(\mathrm{s})\end{array}$ & $\begin{array}{c}\text { Recovery time } \\
(\mathrm{s})\end{array}$ \\
\hline 10 & 3 & 10 \\
20 & 4 & 16 \\
50 & 5 & 20 \\
100 & 6 & 32 \\
\hline
\end{tabular}

would alter the adsorbate-adsorbent interactions and allows unusual selectivity and high sensitivity to $\mathrm{H}_{2} \mathrm{~S}$ gas.

4.4b Sensitivity and operating temperature: Figure 9 compares the variation in the sensitivity of unmodified and $\mathrm{TiO}_{2}$-modified $2 \mathrm{BST}$ films to $\mathrm{H}_{2} \mathrm{~S}$ gas (300 ppm) with operating temperature. Unmodified samples showed weak response $(S=26)$ to $\mathrm{H}_{2} \mathrm{~S}$ gas at $350^{\circ} \mathrm{C}$ while $\mathrm{TiO}_{2-}$ modified films (dipped for $20 \mathrm{~min}$ ) showed maximum response $(S=114)$ at $300^{\circ} \mathrm{C}$. The surface modification enhanced the sensitivity to $\mathrm{H}_{2} \mathrm{~S}$ gas and lowered the operating temperature as well.

\subsection{Selectivity of pure and modified film}

Figure 10 shows the histogram showing selectivities of unmodified and $\mathrm{TiO}_{2}$-modified $2 \mathrm{BST}$ film. It is clear from the histogram that unmodified BST is more selective to $\mathrm{NH}_{3}$ while $\mathrm{TiO}_{2}$-modified is more selective to $\mathrm{H}_{2} \mathrm{~S}$ gas.

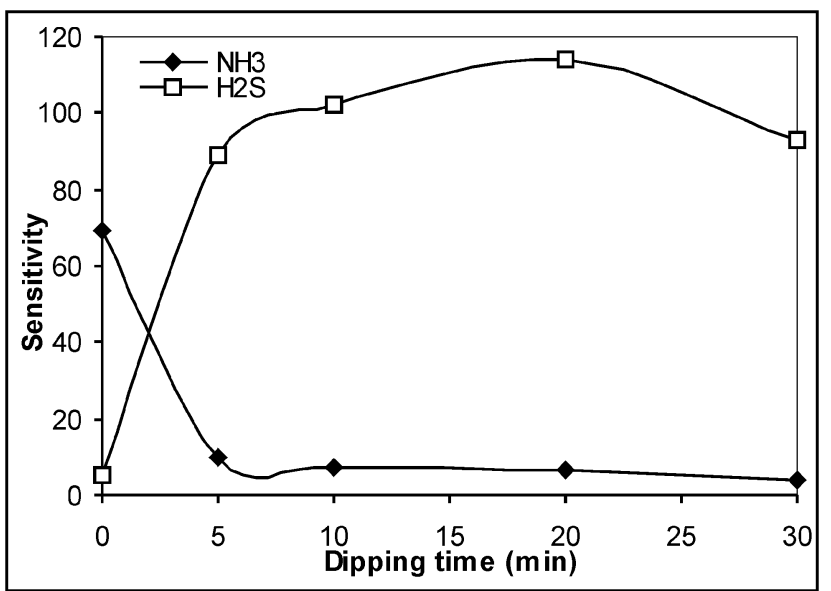

Figure 8. Variation of sensitivity to $\mathrm{NH}_{3}$ and $\mathrm{H}_{2} \mathrm{~S}$ gas with dipping time.

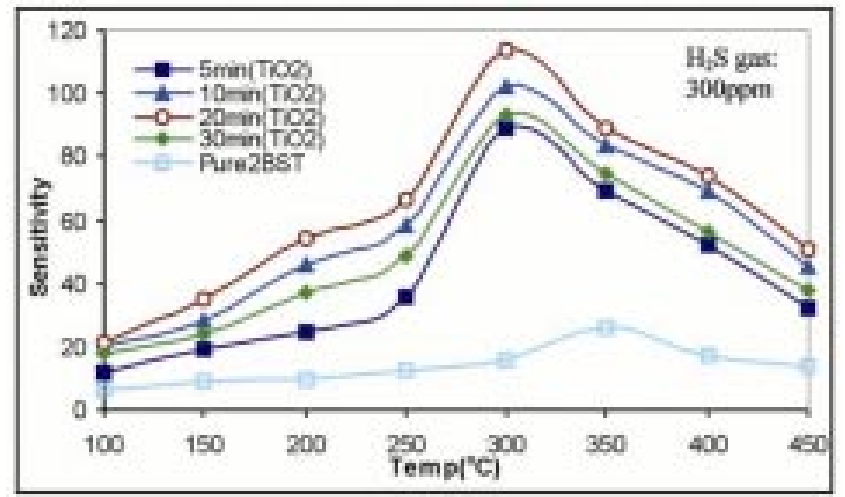

Figure 9. Comparison of sensitivity with unmodified and modified 2 BST films with temperature for $\mathrm{H}_{2} \mathrm{~S}$ gas detection. 
$\mathrm{TiO}_{2}$ misfits on the surface of $2 \mathrm{BST}$ film seem to be responsible for the shift in sensitivity from $\mathrm{NH}_{3}$ to $\mathrm{H}_{2} \mathrm{~S}$ gas.

\subsection{Response and recovery time of $\mathrm{TiO}_{2}$-modified film}

The response and recovery profiles for the most sensitive $\mathrm{TiO}_{2}$-modified 2BST film (20 min) are represented in figure 11 . The response was quick (5 s) and the recovery time was $20 \mathrm{~s}$, at $300^{\circ} \mathrm{C}$ to $\mathrm{H}_{2} \mathrm{~S}$ gas for $30 \mathrm{ppm}$ gas concentration.

\section{Discussion}

\section{$5.1 \quad$ BST as a $\mathrm{NH}_{3}$ sensor}

The sensitivity of $\left(\mathrm{Ba}_{0.87} \mathrm{Sr}_{0 \cdot 13}\right) \mathrm{TiO}_{3}$ to $\mathrm{NH}_{3}$ could be attributed to the high oxygen deficiency and defect density and leads to increased oxygen adsorption. Larger the amount of oxygen adsorbed on the surface, larger would be the oxidizing capability and faster would be the oxidation of $\mathrm{NH}_{3}$ gas. The reactivity of $\mathrm{NH}_{3}$ would have been very large as compared to $\mathrm{H}_{2} \mathrm{~S}$ gas with the surface under same condition. Hydrite $\left(\mathrm{NH}_{3}\right)$ may have lower sensitivity than hydrogen exposed on particular metal oxide under same condition (Windichamann and Mark 1979). The lower response to $\mathrm{NH}_{3}$ may be related to firm binding

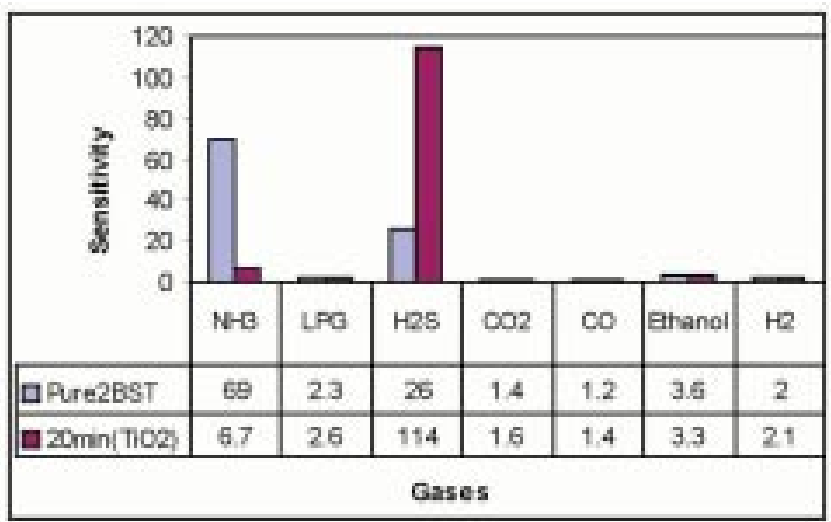

Figure 10. Selectivity of pure and $\mathrm{TiO}_{2}$-modified $(20 \mathrm{~min})$ 2 BST film.

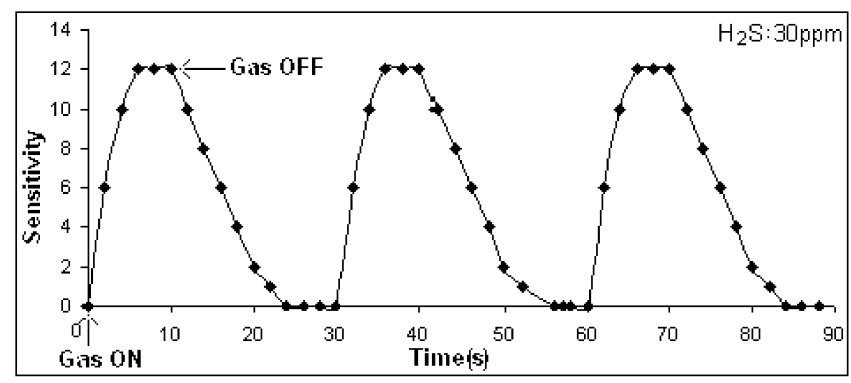

Figure 11. Response and recovery of the $\mathrm{TiO}_{2}$-modified 2 BST film. state preventing fast decomposition and water formation. $\mathrm{NH}_{3}$ could dissociate under certain favourable circumstances into $\left(\mathrm{NH}_{2}\right)^{-}$and $\mathrm{H}^{+}$irreversibly. The reaction of released hydrogen with adsorbed or lattice oxygen could increase the conductance leading to higher sensitivity to $\mathrm{NH}_{3} . \mathrm{NH}_{3}$ undergoes following reaction on exposure to metal surface:

$$
2 \mathrm{NH}_{3}+\mathrm{O}_{\mathrm{ads}}^{-}+\mathrm{O}_{2} \rightarrow 2 \mathrm{NO}_{2}+3 \mathrm{H}_{2} \mathrm{O}+5 e^{-} .
$$

Equation (1) represents the chemical reaction involved in unmodified BST to sense $\mathrm{NH}_{3}$ gas. $\mathrm{NH}_{3}$ molecule has a lone pair of electrons. In comparison with other gases, $\mathrm{NH}_{3}$ can readily donate the unpaired electrons to the metal ions (of base material), which has unfilled orbits to form coordination complex. Furthermore, the coordinated $\mathrm{NH}_{3}$ molecules easily react with oxygen adsorbates $\left(\mathrm{O}_{\mathrm{ads}}^{-}\right)$and the electrons bonded with adsorbed oxygen are returned back into the sensor, increasing the sensor conductivity.

The adsorbed oxygen on the surface of catalyst can be of several forms: $\mathrm{O}_{2}, \mathrm{O}_{2}^{-}, \mathrm{O}^{-}$and $\mathrm{O}^{2-}$. Of these species, $\mathrm{O}_{2}$ is quite inactive because it is in very low concentration. If reducing agent is introduced, the $\mathrm{O}^{-}$disappears very quickly relative to $\mathrm{O}_{2}^{-}$indicating the $\mathrm{O}^{-}$to be more active than $\mathrm{O}_{2}^{-}$. The lattice oxygen, $\mathrm{O}^{2-}$, can also be reactive with the incoming reducing agent.

\section{2 $\mathrm{TiO}_{2}$-modified $\mathrm{BST}$ as $\mathrm{H}_{2} \mathrm{~S}$ gas sensor}

In presence of reducing agent, solids are known to give up lattice oxygen (be reduced-ion exchange) and in presence of oxygen they become oxidized. This semiconductor could be used as gas sensors on redox principle. The ion exchange between a gas and a semiconductor could have a strong influence on the conductivity of the semiconductor. $\mathrm{WO}_{3}$ has been reported (Roy Morrison 1982) to be completely converted to $\mathrm{WS}_{2}$ by a few torr of $\mathrm{H}_{2} \mathrm{~S}$ resulting in increase in conductivity.

Ion exchange mechanism between $\mathrm{TiO}_{2}$ and $\mathrm{H}_{2} \mathrm{~S}$ gas would be the reason behind the change in conductance. When $\mathrm{H}_{2} \mathrm{~S}$ gas is exposed on $\mathrm{TiO}_{2}$ modified BST film surface, the strong affinity of sulphur (electronegativity =

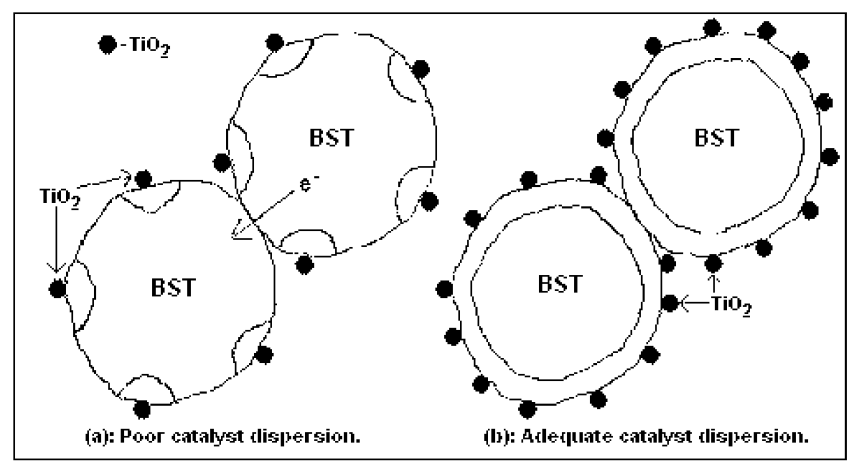

Figure 12. Dispersion of additive. 
2.44) to the $\mathrm{Ti}$ atoms weakens the sulphur-hydrogen bond and facilitates dissociation to an $\mathrm{S}^{2-}$ or an $\mathrm{SH}^{-}$ion and two or one $\mathrm{H}^{+}$ions, $\mathrm{TiO}_{2}$ would be converted into well conducting $\mathrm{TiS}_{2}$.

It is well known that additive lowers the activation energy of the reaction. The lowering of the activation energy can be described by simple illustrations:

$$
\mathrm{TiO}_{2}+2 \mathrm{H}_{2} \mathrm{~S} \rightarrow \mathrm{TiS}_{2}+2 \mathrm{H}_{2} \mathrm{O}
$$

and

$$
\mathrm{H}_{2} \mathrm{~S} \rightarrow \mathrm{H}^{+}+\mathrm{S}^{2-} \text {. }
$$

Ion exchange in (2) requires little energy. $\mathrm{H}_{2} \mathrm{~S}$ could easily be dissociated in presence of $\mathrm{TiO}_{2}$. To dissociate $\mathrm{H}_{2} \mathrm{~S}$ in absence of $\mathrm{TiO}_{2}$ would require large energy input. Larger the dissociation energy larger would be the activation energy. The activation energy required to dissociate $\mathrm{H}_{2} \mathrm{~S}$ would be to a great extent removed (lowered) by using $\mathrm{TiO}_{2}$ misfits as activator.

\subsection{Effect of dipping time on $\mathrm{TiO}_{2}$ dispersion and sensitivity}

Figure 12 illustrates the effect of dispersion of surface additive on the film conductivity. Uniform and optimum dispersion of an additive dominates the depletion of electrons from semiconductor. Oxygen adsorbing on additive (misfit) removes electrons from additive and additive in turn removes electrons from the nearby surface region of the semiconductor and could control the conductivity.

For optimum dipping time $(20 \mathrm{~min})$, the number of $\mathrm{TiO}_{2}$ misfits would be optimum and would disperse uniformly covering the complete film surface (figure 12(a)). Adequate dispersion of $\mathrm{TiO}_{2}$ misfits $(20 \mathrm{~min}$ ) on film surface would produce depletion region on the grain surfaces and conductivity could be monitored systematically. The film conductivity would be very low in air and very high on exposure of $\mathrm{H}_{2} \mathrm{~S}$ gas (due to conversion of $\mathrm{TiO}_{2}$ into $\mathrm{TiS}_{2}$ ) and therefore, the sensitivity would be largest.

For the dipping time smaller than the optimum, the number of $\mathrm{TiO}_{2}$ misfits would be smaller, their dispersion would be poor and the depletion regions would be discontinuous and there would be the paths to pass electrons from one grain to another (figure 12(b)). Due to this, the initial conductance (air) would be relatively larger and in turn, sensitivity would be smaller.

For the dipping time larger than the optimum, the number of $\mathrm{TiO}_{2}$ misfits would be larger. This would mask and resist the gas to reach the base material (BST) giving lower sensitivity.

\section{Conclusions}

(I) The unmodified 2BST film is selective to $\mathrm{NH}_{3}$ sensor at $350^{\circ} \mathrm{C}$.
(II) Sensitivity to $\mathrm{NH}_{3}$ gas increases with increase in film thickness and attains a maximum for $33 \mu \mathrm{m}$ and sensitivity decreases on further increase in thickness.

(III) Unmodified BST thick films were surface modified ( $\mathrm{TiO}_{2}$-modified) using dipping technique.

(IV) $\mathrm{TiO}_{2}$-modified BST sensor is selective to $\mathrm{H}_{2} \mathrm{~S}$ gas suppressing the responses to other gases.

(V) Sensing properties of a particular material could be altered by surface modification.

\section{Acknowledgements}

Authors are grateful to the Principal, Pratap College, Amalner, for providing laboratory facilities. Authors are grateful to Dr P K Khanna, C-MET, Pune, and Dr Dharmadhikari, Department of Physics, University of Pune, Pune, for their valuable cooperation rendered for the characterization of the material.

\section{References}

Agarwal S and Sharma G L 2002 Sensors and Actuators B85 205

Aslam M, Choudhary V A, Mulla I S, Sainkar S R, Mandale A B, Belhekar A A and Vijayamohanan K 1999 Sensors and Actuators A75 162

Cantalini C 2004 Sensors and Actuators B24 1421

Chen X F, Zhu W G and Tan O K 2000 Mater. Sci. \& Engg. B77 177

Clifford P K and Tuma D T 1983 Sensors and Actuators 3233 Groot T T 2004 Sense of contacts 6, Keynote (Netherlands (ECN): Sensor Research at Energy Research Centre)

Haueusler A and Meyer J-U 1996 Sensors and Actuators B34 388

Holc J, Slunečko J and Hrovat M 1995 Sensors and Actuators B26-27 99

Huebner H P and Drost S 1991 Sensors and Actuators B4 463

Imawan C, Solzbacher F, Steffs H and Obermeier E 2000 Sensors and Actuators B64 193

Ishihara T, Kometani K, Hashida M and Takita Y 1991 J. Electrochem. Soc. 138173

Ishihara T, Kometani K, Nishi Y and Takita Y 1995 Sensors and Actuators B28 49

Jain G H and Patil L A 2006 Bull. Mater. Sci. 29403

Jain G H, Patil L A, Wagh M S, Patil D R, Patil S A and Amalnerkar D P 2006 Sensors and Actuators B117 159

Kabayashi T, Haruta M, Sano H and Nakane M 1988 Sensors and Actuators 13339

Kong L and Shen Y 1996 Sensors and Actuators B30 217

Lampe U, Gerblinger J and Meixner H 1995 Sensors and Actuators B25 657

Liao B, Wei Q, Wang K Y and Liu Y X 2001 Sensors and Actuators B80 208

Lundström I, Shivaraman M S and Svensson C M 1975 J. Appl. Phys. 463876

Nakamura Y, Zhang H, Kishimoto A, Okada O and Yanagida $\mathrm{H}$ 1998 J. Electrochem. Soc. 145632

Roy Morrison S 1982 Sensors and Actuators 2329 
Roy S C, Sharma G L, Bhatnagar M C and Samanta S B 2005 Sensors and Actuators B110 299

Sberreglieri G 1995 Sensors and Actuators B23 103

Seiyama T, Kato A, Fujiishi K and Nagatani M 1962 Anal. Chem. 341502

Slunečko J, Holc J, Hrovat M and Čeh M 1992 Sensors and Actuators B7 439

Srivastava R K, Lal P, Dwivedi R and Srivastava S K 1994 Sensors and Actuators B21 213

Tamaki J, Maekawa T, Matsushima S, Miura N and Yamazoe N 1990 Chem. Lett. 19477

Tan O K, Zhu W, Tse M S and Yao X 1999 Mater. Sci. \& Engg. B58 221

Tang Z -T, Zhou Z -G and Zhang Z -T 2003 Sensors and Actuators $\mathbf{B} 93391$

Tao W -H and Tsai C -H 2002 Sensors and Actuators B81 237

Timmer B H 2004 Amino-chip, Ph D Thesis, U. Twente, The Netherlands
Timmer B, Olthus W and Berg A V 2005 Sensors and Actuators B107 666

Wang X, Miura N and Yamazoe N 2000 Sensors and Actuators B66 74

Windichamann H and Mark P 1979 J. Electrochem. Soc. 126627

Winquist A, Spetz M, Armgarth C, Nylander C and Lundström I 1983 Appl. Phys. Lett. 43839

Xu C N, Miura N, Ishida Y, Matuda K and Yamazoe N 2000 Sensors and Actuators B65 163

Yamazoe N 2005 Sensors and Actuators B108 2

Yamazoe N, Kurokawa Y and Seiyama T 1983 Sensors and Actuators 4283

Yan W, Sun L, Lui M and Li W 1991 Acta Scientiarium Naturalium Universitaties Jilinesis 252

Zakrzewska K 2001 Thin Solid Films 391229

Zhou Z -G, Tang Z -L and Zhang Z -T 2003 Sensors and Actuators $\mathbf{B} 93356$

Zhu W, Tan O K, Yan Q and Oh J T 2000 Sensors and Actuators B65 366 